\title{
Higher Expression Level and Lower Toxicity of Genetically Spliced Rotavirus NSP4 in Comparison to the Full-Length Protein in E. coli
}

\author{
Mehdi Sahmani ${ }^{1 \dagger}$, Siavash Azari ${ }^{2 \dagger}$, Majid Tebianian ${ }^{3}$, Nematollah Gheibi ${ }^{4}$, Farzaneh Pourasgari ${ }^{3 *}$ \\ ${ }^{1}$ Department of Clinical Biochemistry and Genetics, Cellular and Molecular Research Center, Qazvin University of Medical \\ Sciences, Qazvin, Iran \\ ${ }^{2}$ Department of Biotechnology, School of Paramedical Sciences, Qazvin University of Medical Sciences, Qazvin, Iran \\ ${ }^{3}$ Department of Biotechnology, Razi Vaccine and Serum Research Institute, Karaj, Iran \\ ${ }^{4}$ Cellular and Molecular Research Center, Qazvin University of Medical Sciences, Qazvin, Iran \\ ${ }^{*}$ Corresponding author: Farzaneh Pourasgari, Department of Biotechnology, Razi Vaccine and Serum Research Institute, Karaj, Iran. Tel: +98-2634570038, \\ Fax: +98-2634552194, E-mail: f.pourasgari@rvsri.ac.ir \\ $\dagger$ These authors contributed equally to this work
}

Received: May 15, 2015; Revised: November 21, 2015; Accepted: February 24, 2016

Background: Rotavirus group A (RVA) is recognized as a major cause of severe gastroenteritis in children and new-born animals. Nonstructural protein 4 (NSP4) is responsible for the enterotoxic activity of these viruses in the villus epithelial cells. Amino acids 114-135 of NSP4 are known to form the diarrhea-inducing region of this viral enterotoxin. Therefore, developing an NSP4 lacking the enterotoxin domain could result in the introduction of a new subunit vaccine against rotaviruses in both humans and animals.

Objectives: The aim of this study is the evaluation of rotavirus A NSP4 expression in E. coli expression system before and after removal of the diarrhea-inducing domain, which is the first step towards further immunological studies of the resulting protein.

Materials and Methods: Splicing by overlap extension (SOEing) PCR was used to remove the diarrhea-inducing sequence from the NSP4 cDNA. Both the full-length (FL-NSP4) and the spliced (S-NSP4) cDNA amplicons were cloned into pET-32c and pGEX-6P-2. Expression levels of the recombinant proteins were evaluated in E. coli BL21 (DE3) by Western blot analysis. In addition, the toxicity of pET plasmids bearing the S-NSP4 and FL-NSP4 fragments was investigated by plasmid stability test.

Results: For FL-NSP4, protein expression was detected for the strain containing the pGEX:FL-NSP4 plasmid, but not for the strain carrying pET:FL-NSP4. Hourly sampling up to $3 \mathrm{~h}$ showed that the protein production decreased by time. In contrast, expression of S-NSP4 was detected for pET:S-NSP4 strain, but not for pGEX:S-NSP4. Plasmid stability test showed that pET:S-NSP4 recombinant plasmid was almost stable, while pET:FL-NSP4 was unstable.

Conclusions: This is the first report of production of rotavirus NSP4 lacking the diarrhea-inducing domain (S-NSP4). SNSP4 shows less toxicity in this expression system and potentially could be a promising goal for rotavirus immunological and vaccine studies in the future.

Keywords: Diarrhea; Enterotoxin; Expression; NSP4; Rotavirus; Splicing by overlap extension PCR

\section{Background}

Rotaviruses are globally the leading cause of severe dehydrating diarrhea in children below 5 years of age. According to WHO estimates, rotaviruses resulted in approximately 453,000 (420,000-494,000) child deaths in 2008 worldwide, mostly in low income countries (1).

Rotaviruses belong to the genus Rotavirus in the family of Reoviridae. Rotavirus virions are nonenveloped forming an icosahedral triple-layered pro- tein capsid the core of which carries the viral genome consisting of 11 segments of double-stranded RNA (dsRNA). The genome is surrounded by a triple-layered capsid and encodes six structural (VP1-VP4, VP6, and VP7) and six nonstructural (NSP1-NSP6) proteins. Nonstructural protein 4 (NSP4) is the enterotoxin of this virus, which plays its role in the villus epithelial cells and causes diarrhea (2).

The non-structural protein 4 (NSP4) is a 175amino-acid enterotoxin with nascent polypeptide MW 
of approximately $20.2 \mathrm{kDa}$, which consists of distinct domains that contribute to its multiple functions. The domain functions include diarrhea-induction, which is attributed to amino acids $114-135$ in the cytoplasmic tail, and calcium binding. A synthetic peptide corresponding to the diarrhea-inducing domain, was shown to induce diarrhea in neonatal mice in a 100 -fold molar excess in comparison to the full-length protein $(3,4)$. However, this suggests that other domains could also influence the diarrhea-induction ability of NSP4 (5). This so-called diarrhea-inducing region forms part of the oligomerization domain (amino acids 95-137), thus contributes directly to the conformation of the functional domain (C-terminus) of NSP4 $(3,6)$. It has also been suggested that a unique conformation is required for optimal function of rotavirus enterotoxin (7). Moreover, the integrins $\alpha 1 \beta 1$ and $\alpha 2 \beta 1$ are receptors for NSP4 in which amino acids 114-130 are responsible for binding to the I domain of $\alpha 1$; and residues 114-135 can block binding of the natural ligand, collagen I, to Integrin $\alpha 2$ (8). This interaction in turn leads to secretion of chloride ions and diarrhea-induction via a phospholipase C (PLC) mediated pathway (9). Therefore, it can be suggested that removing amino acids 114-135 could effectively lower, if not inhibit, the toxicity of NSP4 for two reasons: first, via disrupting the correct functional conformation and oligomerization of the protein and second, via blocking the interaction of NSP4 with integrin receptors.

Several studies have demonstrated successful expression of this protein in eukaryotic cells such as Sf9 cells of Spodoptera frugiperda (10-14). However, expression of the full-length NSP4 in E. coli has been a challenge thus far, due to its toxicity (15-17); while there has been more success with truncated, modified, or mutant NSP4 derivatives $(5,17-21)$.

\section{Objectives}

Here, the expression of the full-length and the spliced forms of NSP4 (FL-NSP4 and S-NSP4, respectively) of rotavirus A RF in E. coli BL21 (DE3) strain carrying recombinant pGEX-6P-2 (pGEX:FL-NSP4) and pET-32c (pET:S-NSP4) are presented. Construction of S-NSP4 is reported for the first time using splicing by overlap extension (SOEing) PCR technique to delete the diarrhea-inducing domain. The full length and the spliced fragments were cloned in two E. coli expression systems and their expressions were characterized by SDS-PAGE and Western blot assays. The purpose of this study is to establish an inexpensive, rapid, and uncomplicated method to pro- duce both proteins for future studies on the structure, function, and immunogenicity of rotavirus NSP4 and its enterotoxin domain. This can be the first step towards the introduction of a subunit rotavirus vaccine.

\section{Materials and Methods}

\subsection{Cell Culture and Virus}

MA104 fetal Rhesus monkey kidney cells were grown in Dulbeco's modified Eagle medium (Gibco, USA) containing 10\% fetal bovine serum (Gibco, USA), penicillin (Sigma-Aldrich, USA) (100 units. $\left.\mathrm{mL}^{-1}\right)$, and streptomycin (Sigma-Aldrich, USA) (0.1 mg.mL-1) at $37^{\circ} \mathrm{C}$ and $5 \% \mathrm{CO}_{2}(22,23)$. After reaching $50 \%$ of confluency, the MA104 cell cultures were infected by rotavirus RF strain and incubated in serumfree DMEM for $24 \mathrm{~h}(24,25)$.

\subsection{Primer Design and PCR Conditions}

Total viral RNA was extracted with QIAzol lysis reagent (Qiagen, Germany) according to manufacturer's protocol, and total cDNA synthesis was carried out by reverse transcription (RT-PDR) with random hexamers. The complete coding DNA sequence of RF rotavirus NSP4 mRNA (GenBank accession number AY116593) was used to design two forward and two reverse primers that amplified FL-NSP4 (535 bp) and S-NSP4 (469 bp). To amplify FL-NSP4, the forward primer F1 (5'-GTGCGGAAAGATGGAAAAGC) and the reverse primer R2 (5'-CATCGCTGCAGTCACTTCTTT TG) were used. However, in order to remove the diarrhea-inducing domain by SOEing PCR (26), the forward primer F2 (5'-GAAATGATTATACGAGCAGTAG AC) and the reverse primer R1 (5'-TGCTCGTATAATC ATTTCTAGCTGACG) were also needed. Finally, two primer pairs, F1-R1 and F2-R2 were used to amplify the large (S1-NSP4) and the small (S2-NSP4) fragments of S-NSP4, respectively. The large fragment (358 bp) encodes amino acids 1-113 of NSP4, while the small fragment (129 bp) encodes amino acids 136175. These two overlapping fragment were joined by SOEing PCR in order to make S-NSP4 (Figure 1). All PCR amplifications were carried out with Taq DNA polymerase PCR kit (Thermo Scientific, USA) and the reagents were used according to the manufacturer's protocol (for $50 \mu \mathrm{L}$ reaction: 50-125 $\mathrm{ng}$ template cDNA (RT-PCR product), $0.2 \mathrm{mM}$ dNTP, $1 \mathrm{X}$ buffer, $1.5 \mathrm{mM} \mathrm{MgCl}_{2}, 4 \mathrm{U} \mathrm{Taq}$ polymerase, and 40 pmol of each primer). To amplify FL-NSP4 and each of the two S1- and S2-NSP4 fragments, the PCR was performed 


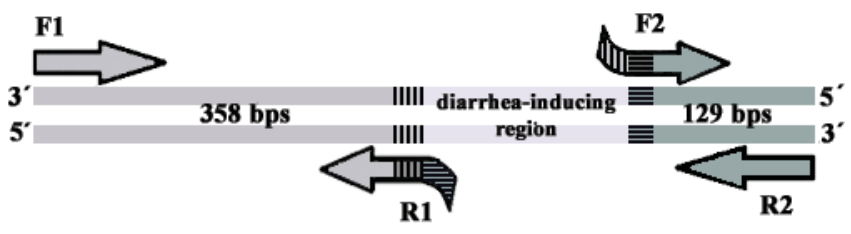

Figure 1. The schematic diagram of the overlapping fragments of S-NSP4. The first 18 nucleotides from the $5^{\prime}$ end $\left(5^{\prime}-3^{\prime}\right)$ of F2 and R1 are complementary. The first 9 nucleotides from the $5^{\prime}$ end of F2 $\left(5^{\prime}-3^{\prime}\right)$ are complementary to the last 9 nucleotides from the $3^{\prime}$ end $\left(3^{\prime}-5^{\prime}\right)$ of the large fragment on the antisense strand, while the first 9 nucleotides from the $5^{\prime}$ end of R1 $\left(5^{\prime}-3^{\prime}\right)$ are complementary to the first 9 nucleotides from the $5^{\prime}$ end $\left(5^{\prime}-3^{\prime}\right)$ of the small fragment on the sense strand. The hatched areas with the same pattern have complementary sequences and each pattern represents 9 nucleotides

$5 \mathrm{~min}$ at $95^{\circ} \mathrm{C}$ (primary denaturation) followed by 35 cycles, each consisting of $95^{\circ} \mathrm{C}$ for $1.5 \mathrm{~min}, 58^{\circ} \mathrm{C}$ for 1 min and $72^{\circ} \mathrm{C}$ for $1 \mathrm{~min}$; and PCR was finalized at $72^{\circ} \mathrm{C}$ for $10 \mathrm{~min}$. The fragments were extracted from agarose gel by HiYield Gel/PCR Fragments Extraction Kit (RBC, Taiwan). S1-and S2-NSP4 were joined by the SOEing PCR, which was performed using equimolar amounts of the large and the small fragments as template DNAs (50-150 ng of each per $50 \mu$ L reaction) without adding any primers. The overlap extension PCR was performed with these conditions: a predenaturation at $95^{\circ} \mathrm{C}$ for $5 \mathrm{~min}$ and 9 cycles of $95^{\circ} \mathrm{C}$ for $1.5 \mathrm{~min}, 50^{\circ} \mathrm{C}$ for $1.5 \mathrm{~min}, 72^{\circ} \mathrm{C}$ for $80 \mathrm{~s}$, and a final 5 min extension at $72^{\circ} \mathrm{C}$. The PCR was paused at $72^{\circ} \mathrm{C}$ and $\mathrm{Taq}$ polymerase (4 $\mathrm{U}$ per $50 \mu \mathrm{L}$ reaction) was added along with $40 \mathrm{pmol}$ of the end primers i.e. F1 and R2, and the PCR was continued with 35 cycles of $95^{\circ} \mathrm{C}$ for $1.5 \mathrm{~min}, 58^{\circ} \mathrm{C}$ for $1 \mathrm{~min}, 72^{\circ} \mathrm{C}$ for $1 \mathrm{~min}$, and a final extension at $72^{\circ} \mathrm{C}$ for $5 \mathrm{~min}$. In brief, the PCR was performed in two consecutive steps: an overlap extension and an amplification. The second step was carried out in order to amplify the entire S-NSP4 that had been produced in the first step (7).

\subsection{Plasmid Construction}

FL- and S-NSP4 were primarily ligated into TA cloning vector (RBC, Taiwan), according to manufacturer's protocol, with T4 DNA ligase (Thermo Scientific, USA) and were transformed into E. coli DH5 $\alpha$ competent cells (28). The cloning was confirmed by growth on LB agar (supplemented with 100 $\mu \mathrm{g} . \mathrm{mL}^{-1}$ ampicillin) and, colony PCR. The plasmids were isolated using GeneJET Plasmid Miniprep Kit (Thermo Scientific, USA). Directions of the inserts were confirmed by R-mapping using restriction enzymes (HindIII and BamHI) and DNA sequencing.
The fragments were excised out of TA vector by EcoRI and SalI. Each fragment was purified from agarose gel and ligated into pET-32c(+) (Novagen, Germany) and pGEX-6P-2 (GE healthcare Life Sciences) at EcoRI/SalI sites with T4 DNA ligase. The new constructs were transformed into E. coli $\mathrm{DH} 5 \alpha$ and finally, the plasmids were extracted and transformed into $E$. coli BL21 (DE3) competent cells. All constructs were extracted from BL21 cells and were sequenced once more for further confirmation.

\subsection{Expression Conditions, SDS-PAGE and Western Blotting}

The four strains of $E$. coli BL21 (DE3) cells (each containing either pET-32c or pGEX-6P-2 constructs of FL- or S-NSP4) were used for protein expression. Cells were cultured overnight in LB broth supplemented with $100 \mu \mathrm{g} \cdot \mathrm{mL}^{-1}$ ampicillin at $37^{\circ} \mathrm{C}$ in a shaking incubator for $16 \mathrm{~h}$. Cultures were diluted 1:100 into fresh LB (containing $200 \mu \mathrm{g} \cdot \mathrm{mL}^{-1}$ ampicillin and 1\% glucose) and grown to reach an $\mathrm{OD}_{600}$ of 0.5-0.7. IPTG $(1 \mathrm{mM})$ was added to induce protein expression $(29,30)$. Samples were collected $30 \mathrm{~min}, 1 \mathrm{~h}, 2 \mathrm{~h}$, and $3 \mathrm{~h}$ post-induction and centrifuged (HERMLE Labortechnik Z $216 \mathrm{MK}$, Germany) for $10 \mathrm{~min}$ at $4{ }^{\circ} \mathrm{C}$ at $12,000 \mathrm{rpm}$. Pellets were re-suspended in lysis buffer ( $8 \mathrm{M}$ urea, $100 \mathrm{mM} \mathrm{NaH}{ }_{2} \mathrm{PO}_{4}, 10 \mathrm{mM}$ Tris, $1 \%$ SDS, and $1 \mathrm{mM}$ EDTA) and sonicated at $100 \%$ amplitude with a $2 \mathrm{~mm}$ probe for 4-6 cycles each consisting of $5 \mathrm{~s}$ of sonication followed by $5 \mathrm{~s}$ intervals. Cell lysates were again centrifuged and supernatants were used for SDS-PAGE (10\%). Western blot was carried out on nitrocellulose membranes using rabbit antiNSP4 antiserum (kindly gifted by Dr. Lennart Svensson, University of Linköping, Sweden) with a dilution ratio of 1:250 and anti-His tag monoclonal antibody (Roche, Germany) with a dilution ratio of 1:2000. Finally, 3,3'-Diaminobenzidine (DAB, Sigma Aldrich, USA) was used to visualize the blots (16).

\subsection{Plasmid Stability Test}

This test was carried out and interpreted according to pET System Manual (31). Briefly, cultures of the strains carrying FL- and S-NSP4 in pET-32c were serially diluted in LB (without ampicillin) immediately before induction. Each strain was plated at a dilution of $10^{-5}$ on an LB agar plate containing both IPTG and ampicillin, and an LB agar plate containing only IPTG. They were also plated at a dilution of $10^{-6}$ on one LB agar plate containing only ampicillin, and one LB agar plate without any additives. 


\section{Results}

\subsection{Virus culture and SOEing PCR}

MA104 cells were infected by bovine rotavirus RF and cell lysates were gathered $24 \mathrm{~h}$ after infection. After RNA extraction from the cell lysates, total cDNA was synthesized. S1-NSP4 (358 bps) and S2-NSP4 (129 bps) were amplified and joined by SOEing PCR. S-NSP4 fragment (469 bps) was generated and amplified. FLNSP4 was simply amplified from the cDNA (Figure 2).

\subsection{Plasmid Construction}

FL- and S-NSP4 were subcloned in both pGEX-6P2 and pET-32c after being cloned in TA cloning vector (Figure 3). Among the sequenced TA:S-NSP4 samples, the sequence showed a single mutation, UUC to UUU both coding for phenylalanine. Sequencing of SNSP4 in the expression vectors confirmed that it was successfully subcloned without any further mutations. The sequence of this S-NSP4 is available at GenBank (accession number KM387404).

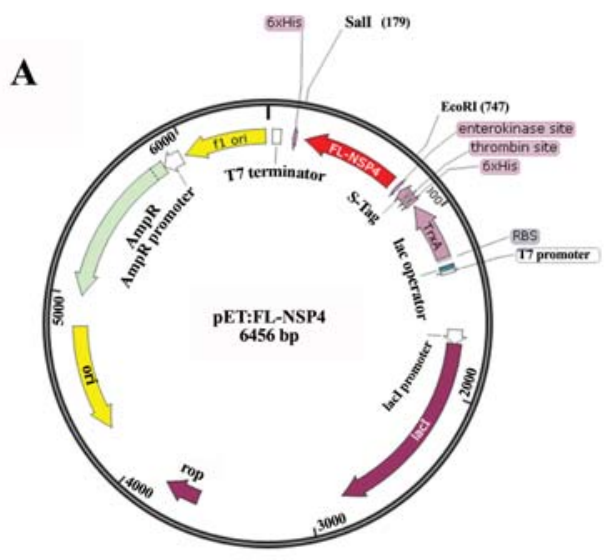

C

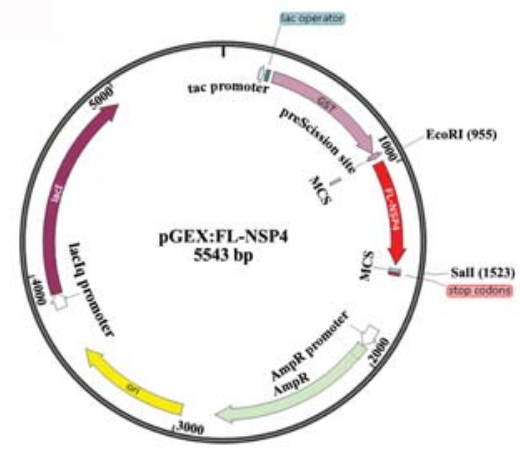

A
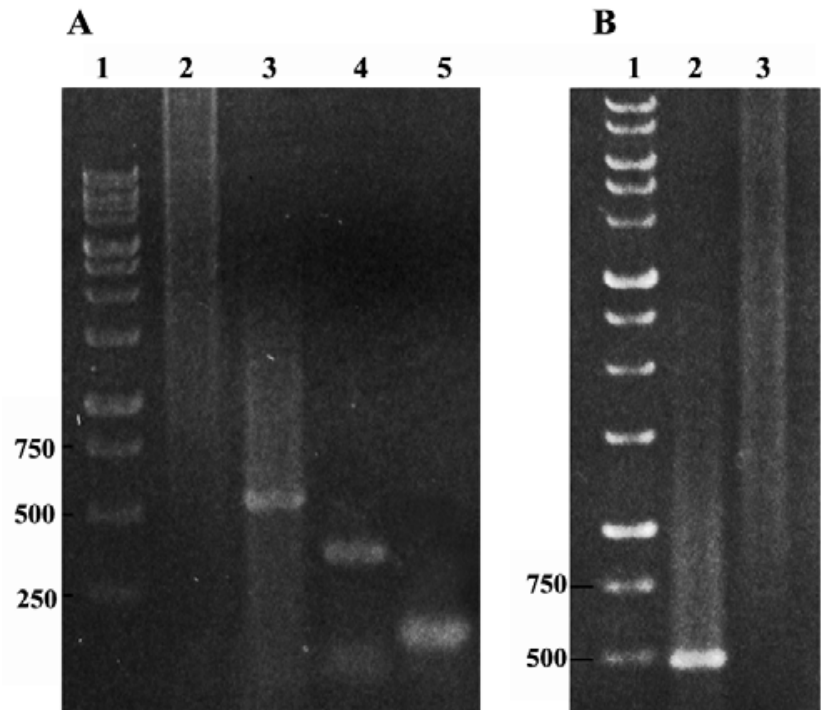

Figure 2. Amplification of FL-NSP4, and S-NSP4 formed by the overlap extension of the S1-NSP4 and S2-NSP4 fragments. A: Lane 1: $1 \mathrm{~kb}$ ladder (Thermo Scientific, USA), lane 2: Negative control, lane 3: FL-NSP4 (535 bp), lane 4: S1-NSP4 (358 bp) and lane 5: S2-NSP4 (129 bp); B: Overlap extension amplification of S-NSP4 (469 bp) (lane 2)

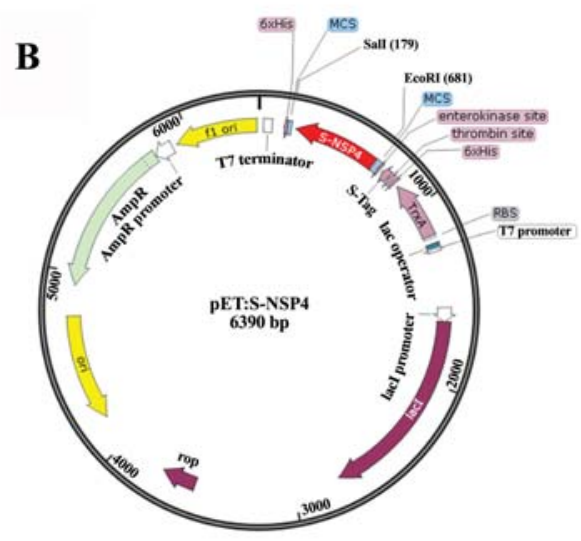

D

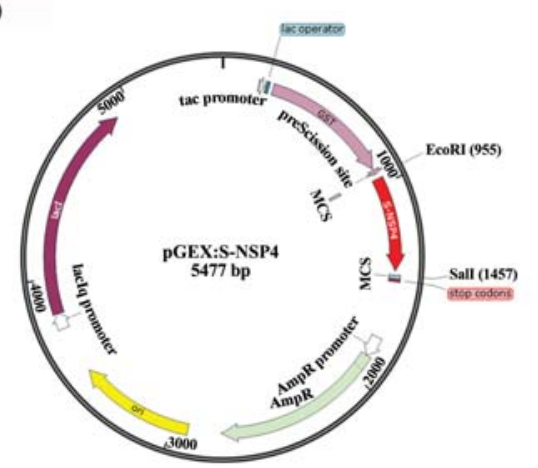

Figure 3. Schematic view of the four expression constructs developed in this study. A: pET:FL-NSP4; B: pET:S-NSP4; C: pGEX:FL-NSP4; D: pGEX:S-NSP4. Maps created by SnapGene ${ }^{\circledR}$ 


\subsection{Production of FL- and S-NSP4 in E. coli BL21 (DE3)}

Protein immunoblot assays using anti-NSP4 antiserum and anti-His tag monoclonal antibody showed that only the pGEX:FL-NSP4 construct could produce the full-length protein (Figure 4). In contrast, S-NSP4 was only detected for the strain containing pET:SNSP4 (Figure 5). The best condition for the expression of FL-NSP4 in the pGEX plasmid was at $1 \mathrm{mM}$ IPTG and $1 \%$ glucose and $30 \mathrm{~min}$ after induction. For SNSP4 in pET-32c plasmid, the optimum expression was obtained at $1 \mathrm{mM}$ IPTG and $1 \%$ glucose $1 \mathrm{~h}$ after induction. Longer incubation time for both showed degradation of the proteins (Figures 4 and 5). According to densitometry analyses (Image J $1.49 \mathrm{v}$, Wayne Rasband, NIH, USA), relative density for pGEX:FL-NSP4 was 1, 0.4, 0.35, and 0.2 at $30 \mathrm{~min}, 1$ $\mathrm{h}, 2 \mathrm{~h}$, and $3 \mathrm{~h}$ after induction, respectively. Also, when the anti-His antibody was used, relative density for pET:S-NSP4 was 1, 1.2, 0.85, and 0.63 at $30 \mathrm{~min}, 1 \mathrm{~h}$, $2 \mathrm{~h}$ and $3 \mathrm{~h}$ after induction, respectively. Almost the same changes in relative density were observed when anti-NSP4 anti-serum detected S-NSP4: 1, 1.2, 0.8 and 0.8 at $30 \mathrm{~min}, 1 \mathrm{~h}, 2 \mathrm{~h}$, and $3 \mathrm{~h}$ after induction, respectively.

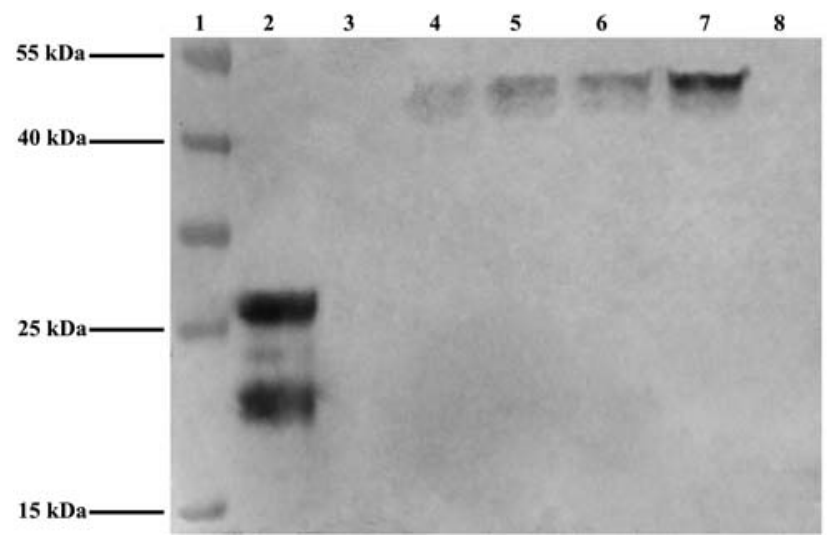

Figure 4. Detection of FL-NSP4 expression. Lane 1, PageRuler ${ }^{\mathrm{TM}}$ Prestained Protein Ladder (Thermo Scientific, USA); Immunoblotting of MA104 lysates (lane 2, infected cells and lane 3 , uninfected cells) and lysates of $E$. coli BL21 containing pGEX:FL-NSP4 (lanes 4, 5, 6, and 7, correspond to $3 \mathrm{~h}, 2 \mathrm{~h}, 1 \mathrm{~h}$, and $30 \mathrm{~min}$ post induction by IPTG, respectively; lane 8 , uninduced). NSP4 was detected using anti-NSP4 antiserum. The expected molecular weight was approximately $49 \mathrm{kDa}$ because of the presence of GST-tag. Faint bands with smaller molecular weights probably correspond to degraded forms of the target protein. More than one bands were observed in MA104 cell lysates probably corresponding to different glycosylation states of NSP4

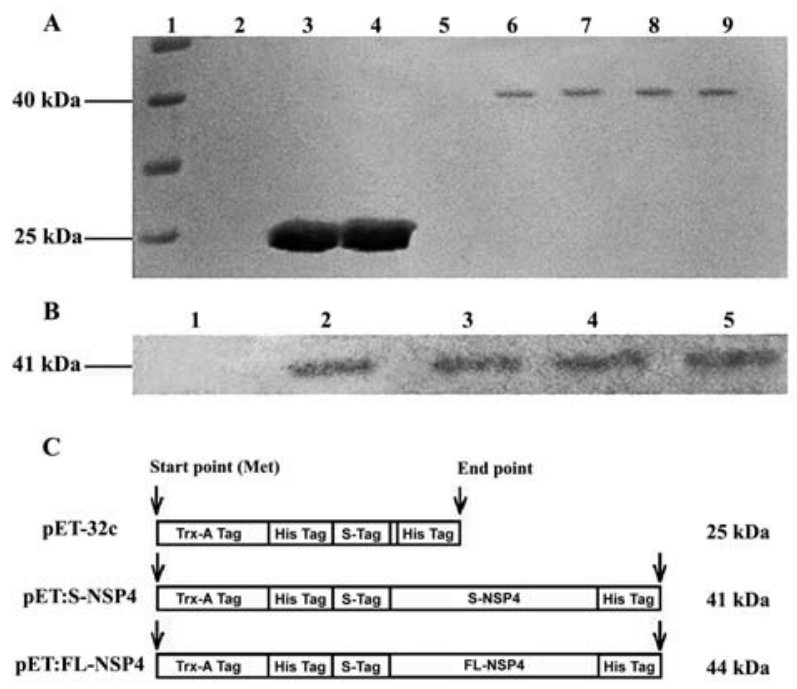

Figure 5. Detection of S-NSP4 Expression. A: Western blots with anti-His tag antibody: Lane 1, PageRuler ${ }^{\mathrm{TM}}$ Prestained Protein Ladder (Thermo Scientific, USA); lysates of E. coli BL21 containing pET-32c (lane 2, uninduced; lane 3, $2 \mathrm{~h}$ post induction; lane 4, $3 \mathrm{~h}$ post induction) and lysates of $E$. coli BL21 containing pET:SNSP4 (lanes 5, 6, 7, 8, and 9 correspond to uninduced, 0.5, 1, 2, and $3 \mathrm{~h}$ post induction by IPTG, respectively). B: Western blots with anti-NSP4 antiserum: lysates of E. coli BL21 containing pET:S-NSP4 (lanes 1, 2, 3, 4, and 5 correspond to uninduced, 0.5, 1,2 , and 3 h post induction by IPTG, respectively). C: Schematic diagram of the expression units in pET-32c, pET:S-NSP4 and pET:FL-NSP4

\subsection{Plasmid Stability}

The cells carrying pET:FL-NSP4 formed 476 and 398 colonies on LB agar containing IPTG and LB agar containing IPTG and ampicillin (both in dilution $10^{-5}$ ), respectively. These cells formed 89 colonies on LB agar and 58 colonies on LB agar containing ampicillin (both in dilution $10^{-6}$ ). In contrast, cells carrying pET:S-NSP4 formed 46 colonies on LB agar containing IPTG and no colonies on LB agar containing IPTG and ampicillin (both in dilution 10-5). These cells formed 56 colonies on LB agar and 50 colonies on LB agar containing ampicillin (both in dilution 10-6) (Table 1).

\section{Discussion}

Human rotavirus A (HRV-A) has been identified as the major causative agent of acute infantile gastroenteritis infecting newborns and children worldwide (32). Due to the absence of efficient anti-rotavirus drugs, efforts are being made to design vaccines to prevent the disease (34). NSP4 can be used to generate effective recombinant vaccines to hamper the effect of HRV-A. Previous studies failed to express the fulllength NSP4 in E. coli using the pET expression sys- 
Table 1. Plasmid stability test for pET:FL-NSP4 and pET:S-NSP4. The number of CFUs on different plates. The test for each strain was carried out separately; and a strain containing $\mathrm{pET}-32 \mathrm{c}$ without any inserts (empty pET) was used as a control each time

\begin{tabular}{lcccc}
\hline Strain & $\begin{array}{c}\text { LB agar } \\
\left(\mathbf{1 0 ^ { - 6 } )}\right.\end{array}$ & $\begin{array}{c}\text { LB agar+ampicillin } \\
\left(\mathbf{1 0 ^ { - 6 }}\right)\end{array}$ & $\begin{array}{c}\text { LB agar+IPTG } \\
\left(\mathbf{1 0}^{-5}\right)\end{array}$ & $\begin{array}{c}\text { LB agar+IPTG+ampicillin } \\
\left(\mathbf{1 0 ^ { - 5 }}\right)\end{array}$ \\
\hline Test 1 & & & & 398 \\
pET:FL-NSP4 & 89 & 58 & 476 & 0 \\
pET & 613 & 538 & 38 & 0 \\
Test 2 & 56 & 50 & 46 & 0 \\
pET:S-NSP4 & 630 & 618 & 44 & 0 \\
pET & & & 46 & \\
\hline
\end{tabular}

tem, but successful expression was reported for Lactococcus lactis (16). The latter expression system seems to be promising and can be used as an alternative expression system (34). Here, expression of the rotavirus enterotoxin (NSP4) was carried out before and after removal of its diarrhea-inducing domain in $E$. coli BL21 DE3. As this protein is made of different domains with distinct functions (3), it has been subject of different studies in full-length, modified, truncated, and mutated forms $(5,9,17,21)$. This protein is toxic for both prokaryotic and eukaryotic (especially mammalian) cells because of disruption of calcium homeostasis and membrane destabilization (29, 35). Successful expression of full-length NSP4 was reported in Sf9 eukaryotic insect cells with higher tolerance to the membrane destabilizing effect of the rotavirus enterotoxin (11). Toxicity of NSP4 for E. coli has already been observed (16), and is most probably because of similarity of the bacterial inner membrane to the membrane of the ER (15). Several studies have demonstrated that NSP4 disrupts the integrity of the ER membrane upon infection with rotavirus or expression of recombinant NSP4 in eukaryotic cells $(11,29$, $35)$. Considering these facts, it is difficult to produce the full-length NSP4 or its truncated domains in $E$. coli, when they contain regions that contribute to cytotoxicity (15).

In attempts made to express FL- and S- NSP4 in pET-32c, no protein was produced for FL-NSP4. Further, pGEX-6P-2 was used to seek for probable expression. In total, four strains of E. coli BL21 (DE3) containing recombinant plasmids of FL- or S-NSP4 in both pET-32c and pGEX-6P-2 were prepared. Protein expression was only detected in pGEX:FL-NSP4 and pET:S-NSP4. The best expression results were obtained by adding twice the initial concentration of ampicillin $\left(200 \mu \mathrm{g} \cdot \mathrm{mL}^{-1}\right.$ instead of $\left.100 \mu \mathrm{g} \cdot \mathrm{mL}^{-1}\right)$ and $1 \%$ glucose to the culture medium. The logic behind this condition was to impose a tighter selective force on plasmid-carrying strains by using higher concentrations of ampicillin, and to avoid leaky expression by using glucose (30).

According to the number of colony forming units (CFUs) (Table 1), the proportion of the cells carrying pET:S-NSP4 that formed colonies on LB agar plates containing only IPTG to the number of the cells that grew on LB agar alone was 46/560 (less than $2 \%$ ). Furthermore, the proportion of the same cells that formed colonies on LB agar containing both IPTG and antibiotic to the number of the cells that grew on LB agar alone was 0/560 (less than 0.01\%). Accordingly, cells containing pET:S-NSP4 were stable. Nevertheless, these proportions for pET:FL-NSP4 were 476/890 (more than 2\%) and 398/890 (more than $0.01 \%$ ), respectively, which show that the cells containing pET:FL-NSP4 were unstable (27).

According to plasmid stability test, cells carrying the pET:FL-NSP4 construct were unstable, which explains the reason FL-NSP4 was not detected in Western blots. These results are in accordance with the previous studies which had reported unsuccessful expression of the same protein using $\mathrm{pET}$ expression vectors (16). In contrast, the pET:S-NSP4 recombinant plasmid was almost stable. The $41 \mathrm{kDa}$ band that was observed for S-NSP4 was weak in comparison to the control (pET plasmid alone) in Western blots, probably due to the toxicity of S-NSP4. A possible explanation could be that although the diarrhea-inducing domain (aa 114-135) was removed, still the viroporin domain (aa 47-92) which includes the membrane-destabalizing region (aa 55-69) was present (3), and this may have lead to cytotoxicity. However, this hypothesis, i.e. the cytotoxic effect of viroporin domain alone even after removal of the diarrhea-inducing region, has to be further investigated. FL-NSP4 was detected in the pGEX:FL-NSP4 strain, and Western blot showed that the amount of this $49 \mathrm{kDa}$ protein decreased by time. 
This decrease could have been resulted by the toxicity of the protein, which was observed in previous studies and/or degradation, which can be because of the release of cellular proteases due to the membrane destabilizing activity of NSP4. On the contrary, no track of S-NSP4 was detected in the pGEX:S-NSP4 strain cell lysates, and this may be the result of higher toxicity level of the resulting S:NSP4 fusion protein from pGEX as well as protein degradation. Our hypothesis is that the interactions between the protein fusion tags, constitutively encoded by each plasmid, and these recombinant proteins could cause conformational changes, which may affect toxicity and stability of each fusion product. Therefore, this may be another reason why each plasmid could only express one of the two recombinant proteins instead of both of them.

\section{Conclusions}

Expression of NSP4 and its modified derivatives is necessary for both structural-functional and immunological studies; therefore, it is important to overcome hurdles such as cytotoxicity to be able to produce decent amounts of the desired proteins. This study was an effort to produce rotavirus NSP4 before and after removal of its diarrhea-inducing region in $E$. coli. We managed to produce FL- and S-NSP4 in pGEX-6P-2 and pET-32c, respectively. However, further studies are needed to optimize the expression and to determine the folding, the functionality, and the toxicity of these proteins in different hosts and in relation to different fusion tags. Therefore, fusion tags should be considered and chosen carefully in expression studies because they play an important role in the final folding and thus the stability and function of any given recombinant protein. Apart from the effect of fusion proteins, the immunogenicity of NSP4 may be affected by removal of its enterotoxin domain. This could also be attributed to the function of this domain or the conformational changes that its removal imposes on the resulting protein. No previous studies have reported the expression of a modified version of NSP4 that lacks the diarrheainducing region in $E$. coli. The structural, functional, and immunological characteristics of the recombinant protein that we expressed in this study is open to further investigations.

\section{Acknowledgements}

This work has been kindly supported by Razi Vaccine and Serum Research Institute, and Qazvin University of Medical Sciences. All the experiments were carried out in Department of Biotechnology, Razi Vaccine and Serum Research Institute.

\section{References}

1. Rotavirus vaccines WHO position paper: January 2013Recommendations. Vaccine. 2013;31(52):6170-6171. DOI: 10.1016/j.vaccine.2013.05.037

2. Estes MK, Kapikian AZ. Rotaviruses. In: Knipe DM, Howley PM, editors. Fields Virology. 5 ed. Philadelphia,PA. Lippincott Williams \& Wilkins. 2007,p:1917-1974

3. Hu L, Crawford SE, Hyser JM, Estes MK, Prasad BV. Rotavirus non-structural proteins: structure and function. Curr Opin Virol. 2012;2(4):380-388. DOI: 10.1016/j.coviro.2012.06.003

4. Ball JM, Tian P, Zeng CQ, Morris AP, Estes MK. Age-dependent diarrhea induced by a rotaviral nonstructural glycoprotein. Science. 1996;272(5258):101-104. DOI: 10.1126/science.272.5258.101

5. Jagannath MR, Kesavulu MM, Deepa R, Sastri PN, Kumar SS, Suguna K, et al. N- and C-terminal cooperation in rotavirus enterotoxin: novel mechanism of modulation of the properties of a multifunctional protein by a structurally and functionally overlapping conformational domain. J Virol. 2006;80(1):412425. DOI: 10.1128/JVI.80.1.412-425.2006

6. Bowman GD, Nodelman IM, Levy O, Lin SL, Tian P, Zamb TJ, et al. Crystal structure of the oligomerization domain of NSP4 from rotavirus reveals a core metal-binding site. $J \mathrm{Mol}$ biol. 2000;304(5):861-871. DOI: 10.1006/jmbi.2000.4250

7. Rajasekaran D, Sastri NP, Marathahalli JR, Indi SS, Pamidimukkala K, Suguna K, et al. The flexible C terminus of the rotavirus nonstructural protein NSP4 is an important determinant of its biological properties. J Gen Virol. 2008;89(6):1485-1496. DOI: 10.1099/vir.0.83617-0

8. Seo NS, Zeng CQ-Y, Hyser JM, Utama B, Crawford SE, Kim KJ, et al. Integrins $\mathrm{a} 1 \mathrm{~b} 1$ and $\mathrm{a} 2 \mathrm{~b} 1$ are receptors for the rotavirus enterotoxin. Proceedings of the National Academy of Sciences. 2008;105(26):8811-8818. DOI: 10.1073/pnas.0803934105

9. Hyser JM, Estes MK. Rotavirus vaccines and pathogenesis: 2008. Current Opinion in Gastroenterology. 2008;25(1):3643. DOI: 10.1097/MOG.0b013e328317c897

10. Dong Y, Zeng CQ, Ball JM, Estes MK, Morris AP. The rotavirus enterotoxin NSP4 mobilizes intracellular calcium in human intestinal cells by stimulating phospholipase C-mediated inositol 1,4,5-trisphosphate production. Proc Natl Acad Sci USA. 1997;94(8):3960-3965.

11. Tian P, Estes MK, Hu Y, Ball JM, Zeng CQ, Schilling WP. The rotavirus nonstructural glycoprotein NSP4 mobilizes $\mathrm{Ca}^{2+}$ from the endoplasmic reticulum. J Virol. 1995;69(9):57635772.

12. Zhang M, Zeng CQ, Morris AP, Estes MK. A functional NSP4 enterotoxin peptide secreted from rotavirus-infected cells. J Virol. 2000;74(24):11663-11670. DOI: 10.1128/JVI.74.24.1166311670.2000

13. Morris AP, Scott JK, Ball JM, Zeng CQ-Y, O’Neal WK, Estes MK. NSP4 elicits age-dependent diarrhea and $\mathrm{Ca}^{2+}$-mediated $\mathrm{I}^{-}$influx into intestinal crypts of CF mice. Am J Physiol. 1999;277(2):G431-G444

14. Johansen K, Hinkula J, Espinoza F, Levi M, Zeng C, Ruden U, et al. Humoral and cell-mediated immune responses in humans to the NSP4 enterotoxin of rotavirus. J Med Virol. 1999;59(3):369377. DOI: 10.1002/(SICI)1096-9071(199911)59:3<369::AID- 
JMV18>3.0.CO;2-N

15. Browne EP, Bellamy AR, Taylor JA. Membrane-destabilizing activity of rotavirus NSP4 is mediated by a membrane-proximal amphipathic domain. J Gen Virol. 2000;81(8):1955-1959. DOI: 10.1099/0022-1317-81-8-1955

16. Enouf V, Langella P, Commissaire J, Cohen J, Corthier G. Bovine rotavirus nonstructural protein 4 produced by Lactococcus lactis is antigenic and immunogenic. Appl Environ Microbiol. 2001;67(4):1423-1428. DOI: 10.1128/AEM.67.4.1423-1428.200 1

17. Ray P, Malik J, Singh RK, Bhatnagar S, Bahl R, Kumar R, et al. Rotavirus nonstructural protein NSP4 induces heterotypic antibody responses during natural infection in children. $J$ Infect Dis. 2003;187(11):1786-1793. DOI: 10.1086/375243

18. Hyser JM, Zeng CQ, Beharry Z, Palzkill T, Estes MK. Epitope mapping and use of epitope-specific antisera to characterize the VP5* binding site in rotavirus SA11 NSP4. Virology. 2008;373(1):211-228. DOI: 10.1016/j.virol.2007.11.021

19. Deepa R, Durga Rao C, Suguna K. Structure of the extended diarrhea-inducing domain of rotavirus enterotoxigenic protein NSP4. Arch Virol. 2007;152(5):847-859. DOI: 10.1007/s00705006-0921-x

20. Rajasekaran D, Sastri NP, Marathahalli JR, Indi SS, Pamidimukkala K, Suguna K, et al. The flexible C terminus of the rotavirus non-structural protein NSP4 is an important determinant of its biological properties. J Gen Virol. 2008;89(6):1485-1496. DOI: 10.1099/vir.0.83617-0

21. Vizzi E, Calvino E, Gonzalez R, Perez-Schael I, Ciarlet M, Kang $\mathrm{G}$, et al. Evaluation of serum antibody responses against the rotavirus nonstructural protein NSP4 in children after rhesus rotavirus tetravalent vaccination or natural infection. Clin Diagn Lab Immunol. 2005;12(10):1157-1163. DOI: 10.1128/CDLI.12.10.1157-1163.2005

22. Hasenack BS, Botelho MVJ, Lauretti F, Melo FLd, Orlandi JM, Linhares REC, et al. The effect of concanavalin A on the replication of rotavirus (SA-11) in cell culture. Braz Arch Biol Technol. 2002;45:125-135. DOI: 10.1590/S1516-89132002000200003

23. Pourasgari F, Ahmadian S, Hassan ZM, Mahdavi M, Salmanian $\mathrm{AH}$, Sarbolouki MN, et al. Intranasal immunization of mice with VP2 DNA of human rotavirus a induces cellular and humoral immunity. Acta virol. 2008;52(4):225-229.

24. Arnold M, Patton JT, McDonald SM. Culturing, storage and quantification of rotaviruses. Curr Protoc Microbiol. 2009; 15:C:15C.3:15C.3.1-15C.3.24. DOI: 10.1002/97804717292 59.mc1 5c03s 15

25. Pourasgari F, Ahmadian S, Salmanian AH. Expression and characterization of VP2 protein of human rotavirus a in a mammalian lung cell line. Acta Virol. 2007;51(4):261.

26. Horton RM, Cai ZL, Ho SN, Pease LR. Gene splicing by overlap extension: tailor-made genes using the polymerase chain reaction. BioTechniques. 1990;8(5):528-535.

27. Heckman KL, Pease LR. Gene splicing and mutagenesis by PCR-driven overlap extension. Nat Protoc. 2007;2(4):924932. DOI:10.1038/nprot.2007.132

28. Sambrook J, Russell DW. Molecular Cloning. A Laboratory manual. 3ed. New York, USA: Cold Spring Harhor Press; 2001.

29. Hyser JM, Collinson-Pautz MR, Utama B, Estes MK. Rotavirus disrupts calcium homeostasis by NSP4 viroporin activity. $m$ Bio. 2010;1(5):e00265-10. DOI: 10.1128/mBio.00265-10

30. Suter-Crazzolara C, Unsicker K. Improved expression of toxic proteins in Escherichia coli. BioTechniques. 1995;19:202204.

31. Novagen website. pET System Manual $10^{\text {th }}$ ed. Available from: http://wolfson.huji.ac.il/purification/PDF/Expression Systems/NovagenPETSys. 2002.

32. Kapikian AZ, Hoshino Y, Chanock RM. Rotaviruses. In: Knipe $D$, Howley M, editors. Fields Virology. $4^{\text {th }}$ ed. Philadelphia, PA: Lippincott. Williams \& Wilkins; 2001;p:1787-1833.

33. Pourasgari F, Ahmadian S, Salmanian AH, Sarbolouki MN, Massumi M. Low cytotoxicity effect of dendrosome as an efficient carrier for rotavirus VP2 gene transferring into a human lung cell line: dendrosome, as a novel intranasally gene porter. Mol Biol Rep. 2009;36(1):105-109. DOI: 10. 1007/s11033-007-9157-4

34. Marelli B, Magni C. A simple expression system for Lactococcus lactis and Enterococcus faecalis. World J Microbiol Biotechnol. 2010;26(6):999-1007. DOI: 10.1007/ s11274-009-0262-5

35. Newton K, Meyer JC, Bellamy AR, Taylor JA. Rotavirus nonstructural glycoprotein NSP4 alters plasma membrane permeability in mammalian cells. $J$ Virol. 1997;71(12):9458-9465. 